\title{
Interação entre genótipos de feijoeiro e ambientes no Estado de Pernambuco: estabilidade, estratificação ambiental e decomposição da interação
}

\section{Interaction between common bean genotypes and environments in Pernambuco State: stability, environmental stratification and decomposition of interaction}

\author{
Helton Santos Pereira ${ }^{1 *}$; Antônio Félix da Costa $^{2}$; Leonardo Cunha Melo ${ }^{3}$; \\ Maria José Del Peloso ${ }^{3}$; Luís Cláudio de Faria ${ }^{3}$; Adriane Wendland ${ }^{3}$
}

\section{Resumo}

Os objetivos desse trabalho foram verificar a ocorrência de interação genótipos $\times$ ambientes $(\mathrm{G} \times \mathrm{E})$ em feijoeiro-comum no Estado de Pernambuco, identificar genótipos com alta adaptabilidade e estabilidade de produção, realizar a estratificação ambiental e identificar quais fatores são mais importantes para a interação. Foram realizados 10 ensaios em blocos ao acaso, com três repetições, conduzidos na época de semeadura das águas, em 2007 e 2008. Os ensaios foram compostos por 16 genótipos com quatro diferentes tipos de grãos: "carioca" (creme com listras marrons), preto, mulatinho e "rajado" (creme com listras vermelhas). Foram obtidos dados de produtividade de grãos, massa de 100 grãos, reação a antracnose, arquitetura de plantas e tolerância ao acamamento. Os dados de produtividade de grãos foram submetidos às análises de variância, à análise de adaptabilidade e estabilidade pela metodologia de Annicchiarico, à análise de fatores para estratificação ambiental e à análise conjunta com decomposição da interação $\mathrm{G} \times \mathrm{A}$ em genótipos $\times$ anos e genótipos $\times$ locais. Foi observada interação G $\times$ E. Os genótipos BRS Pontal, de grãos carioca, BRS Campeiro e BRS Esplendor, de grãos pretos e BRS Agreste, de grãos mulatinhos, reúnem alta adaptabilidade, estabilidade e produtividade de grãos em Pernambuco. Os locais utilizados para avaliação de feijoeiro-comum nessa região são informativos e, portanto, não devem ser eliminados. Existe interação entre os genótipos, locais e anos nessa região, o que faz com que os genótipos tenham que ser avaliados no maior número possível de locais e anos, nessa ordem de importância.

Palavras-chave: Phaseolus vulgaris, produtividade de grãos, massa de cem grãos

\footnotetext{
Abstract

The objetives of this work were to verify the occurrence of interaction between common bean genotypes and environments $(\mathrm{G} \times \mathrm{E})$ in Pernambuco state, and to identify genotypes with high yield adaptability and stability, and to perform environmental stratification and determination of which factors are more important to interaction. Ten trials were conducted in a randomized complete blocks design with three

${ }^{1}$ Pesquisador, Embrapa Arroz e Feijão, C P 179, CEP 75375-000. Santo Antônio de Goiás, GO. E-mail: helton.pereira@embrapa. br

2 Pesquisador, Instituto Agronômico de Pernambuco, CEP 50761-000. Recife, PE. E-mail: felix.antonio@ipa.br

${ }^{3}$ Pesquisadores, Embrapa Arroz e Feijão, C P 179, CEP 75375-000. Santo Antônio de Goiás, GO. E-mail: leonardo.melo@ embrapa.br; mariajose.peloso@embrapa.br; luis.faria@embrapa.br; adriane.wendland@embrapa.br

${ }^{*}$ Autor para correspondência
} 
replications during the rainy seasons of 2007 and 2008. Each trial was composed by 16 genotypes from four different grain types: "carioca" (cream with brown stripes), black, cream and "rajado" (cream with red stripes). The data obtained were: grain yield, weight of one hundred grains, anthracnose reaction, plant architecture and lodging tolerance. Grain yield data were used for analysis of variance, for stability and adaptability analysis according to the methodology proposed by Annichiarico, for factor analysis to environmental stratification, and for joint analysis with decomposition of $\mathrm{G} \times \mathrm{E}$ interaction in genotypes by years and genotypes by locals. $\mathrm{G} \times \mathrm{E}$ interactions were observed. The genotypes BRS Pontal, of carioca- type, BRS Campeiro and BRS Esplendor, of black-type, and BRS Agreste, of mulatinhotype combine high adaptability, stability and grain yield in Pernambuco. Locals used to common bean evaluation in this region were informative and, therefore, must not to be eliminated. There is interaction between genotypes, locals and years in this region, showing that genotypes must be evaluated in larger possible number of locals and years, in this importance order.

Key words: Phaseolus vulgaris, grain yield, weight of 100 grains

\section{Introdução}

Historicamente, a produção de feijão (Phaseolus vulgaris L.) no Brasil é concentrada nas regiões Sul e Sudeste, representando 36\% e 33\% da produção, respectivamente (FEIJÃO, 2011). A região Nordeste responde por $14 \%$ dessa produção, representando 403.772 t em 2009. Essa produção vem diminuindo com os anos, sendo de 557.059 t em 1989.

A produtividade no nordeste $\left(600 \mathrm{~kg} \mathrm{ha}^{-1}\right)$ é inferior a das principais regiões produtoras (1.205 kg.ha ${ }^{-1}$ no Sul e 1.490 kg.ha' ${ }^{-1}$ no sudeste) (FEIJÃO, 2011). O Estado de Pernambuco é o segundo maior produtor do nordeste, com $53.526 \mathrm{t}$ em 107.008 ha e produtividade média de $500 \mathrm{~kg} \cdot \mathrm{ha}^{-1}$ e a produção é concentrada na época das águas, (semeadura entre fevereiro e abril). Um dos prováveis motivos para a diminuição na produção e para a pequena produtividade é a utilização de genótipos antigos, com baixos potenciais produtivos e suscetíveis a estresses bióticos e abióticos, o que pode ser explicado pelo fato de que poucos programas de melhoramento têm atuado nessa região, atualmente. Assim, é importante identificar novos genótipos bem adaptados a essa região, tanto para utilização pelos produtores, quanto para utilização como genitores em programas de melhoramento regionais.

O feijoeiro-comum nessa região é cultivado em diferentes sistemas de cultivo e, consequentemente, a interação genótipos $\times$ ambientes $(\mathrm{G} \times \mathrm{E})$ é relevante, como relatado em vários trabalhos, especialmente para a produtividade de grãos (RAMALHO; ABREU; SANTOS, 1998; GONÇALVES et al., 2009). Além da produtividade de grãos, outras características são essenciais para a aceitação de novas genótipos, como resistência à doenças, porte ereto de plantas, tolerância ao acamamento e tamanho dos grãos (MELO et al., 2007). Assim, alternativas para amenizar o efeito da interação GxE devem ser buscadas, e entre essas, merecem destaque: a identificação de genótipos adaptadas/estáveis, utilizando-se metodologias de análise de estabilidade/adaptabilidade (CRUZ; REGAZZI, 2001); a identificação de locais que fornecem informações redundantes utilizando-se a estratificação ambiental, que possibilita a exclusão de locais redundantes; e a decomposição da interação $\mathrm{G} \times \mathrm{E}$ em seus fatores, ajudando a determinar quais fatores são mais importantes.

Estudos de estabilidade/adaptabilidade têm auxiliado na indicação de genótipos para diversas regiões (MELO et al., 2007; PEREIRA et al., 2009a); DOMINGUES et al., 2013). Entretanto, poucos estudos foram realizados com o feijoeirocomum no Nordeste (CARVALHO et al., 2008) e não foram encontrados estudos em Pernambuco. Entre as metodologias de análise de estabilidade/ adaptabilidade, o método de Annicchiarico (1992) avalia a estabilidade por meio do risco associado em relação à adoção dos genótipos e ainda possibilita o detalhamento dessa informação para ambientes favoráveis e desfavoráveis. 
Estudos de estratificação ambiental para feijoeirocomum foram realizados em algumas regiões, como: São Paulo (CARBONELL; POMPEU, 1997), Paraná/Santa Catarina (BERTOLDO et al., 2009; PEREIRA et al., 2010a) e Goiás/Distrito Federal (PEREIRA et al., 2010b), entretanto, não foram encontrados estudos para o nordeste. Da mesma forma, estudos sobre decomposição da interação genótipos $\times$ ambientes foram realizados para Minas Gerais (RAMALHO; ABREU; SANTOS, 1998), Paraná/Santa Catarina (PEREIRA et al., 2010c) e Goiás/Distrito Federal (PEREIRA et al., 2011), não sendo encontrados estudos no nordeste.

O objetivo desse trabalho foi estudar a interação genótipos $\times$ ambientes em Pernambuco, identificando: genótipos de feijoeiro-comum com alta adaptabilidade/estabilidade; locais redundantes na rede de avaliação; e quais fatores são mais importantes para a interação.

\section{Material e Métodos}

Cada ensaio foi constituído de 16 genótipos de feijoeiro-comum de diferentes tipos de grãos (BRS Pontal, Princesa, BRSMG Pioneiro, BRS Estilo, BRS Requinte, BRS Cometa, Pérola e BRS Horizonte, de grãos carioca; BRS Campeiro, BRS Esplendor, BRS Valente, BRS Grafite e BRS Supremo, de grãos pretos; BRS Marfim e BRS Agreste, de grãos mulatinhos; e BRS Radiante, de grãos rajados). Detalhes sobre estes genótipos são encontrados em Del Peloso et al. (2009), Melo et al. (2010) e Costa et al. (2011). Os ensaios foram conduzidos nos anos de 2007 e 2008, em 10 ambientes no Estado de Pernambuco, na época de semeadura das águas (semeadura entre fevereiro e maio), em blocos ao acaso com três repetições e parcelas de quatro linhas de quatro metros de comprimento, com espaçamento de $0,5 \mathrm{~m}$ entre linhas. Os ambientes utilizados foram: São João, Caruaru, Arco Verde e Belém do São Francisco, na safra das águas/2007 e águas/2008; e Petrolina, com dois ensaios na safra das águas/2008.
Foram realizadas avaliações para produtividade ( $\mathrm{kg} \mathrm{ha}{ }^{-1}$ ) em todos os experimentos e outras características agronômicas, como massa de 100 grãos (M100) em cinco experimentos, arquitetura de plantas (ARQ) em dois experimentos, tolerância ao acamamento (ACA) em cinco experimentos e reação à antracnose (ANT) em quatro experimentos. A reação à antracnose, a arquitetura de plantas e a tolerância ao acamamento foram avaliadas por escalas de notas variando de 1 a 9 , sendo 1 o fenótipo totalmente desejado e 9 o fenótipo totalmente indesejado (MELO, 2009). Os dados oriundos de notas não foram analisados estatisticamente, pois não atenderam às pressuposições para análise de variância. Entretanto, serviram como informação complementar às análises estatísticas para produtividade de grãos, que caracteriza, mais detalhadamente, o comportamento agronômico dos genótipos avaliados.

Os dados de produtividade e massa de cem grãos de cada ensaio foram submetidos à análise de variância, considerando o efeito de tratamentos como fixo. As médias dos genótipos foram comparadas pelo teste de Scott-Knott a 10\% de probabilidade. Esse nível de significância foi utilizado para diminuir a probabilidade de ausência de discriminação entre genótipos devido ao erro tipo II. Segundo Zimmermann (2004), esse procedimento é recomendável quando são esperadas pequenas diferenças entre os tratamentos, como no caso de ensaios com genótipos elite.

Além disso, para a produtividade de grãos foram realizadas outras análises, que estão descritas logo abaixo. Foi estimada a acurácia seletiva (RESENDE; DUARTE, 2007), por meio das expressões: $\mathrm{AS}=\left(1-\frac{1}{F_{c}}\right)^{0,5}$, para $\mathrm{F}_{\mathrm{c}}<1$, em que $\mathrm{F}_{\mathrm{c}}$ é o valor do teste $\mathrm{F}$ para genótipos. A acurácia seletiva foi utilizada para avaliar a precisão experimental, conforme preconizado por Resende e Duarte (2007) e Cargnelutti Filho, Storck e Ribeiro (2009), visto que a AS é uma medida independente 
da média dos experimentos, o que não ocorre com o coeficiente de variação.

Foram realizadas análises conjuntas dos ensaios para cada ano e também com os dois anos, com o efeito de ambientes como aleatórios. Também foram realizadas análises conjuntas dos oito ensaios conduzidos nos quatro locais onde houve ensaios nos dois anos, para decomposição da interação $\mathrm{G} \times \mathrm{E}$ em genótipos $\times$ locais e genótipos $\times$ anos. Nesse caso, os efeitos de genótipos, locais e anos foram considerados fixos. Sempre que a razão entre o maior e o menor quadrado médio do resíduo foi superior a sete, indicativo de que as variâncias residuais não foram homogêneas (PIMENTEL-GOMES, 2000), procedeu-se o ajuste dos graus de liberdade do erro médio e da interação, conforme o método de Cochran (1954). Foram utilizados os aplicativos Genes (CRUZ, 2001) e Sisvar (FERREIRA, 1999) para realização das análises estatísticas.

Para a identificação da importância de cada fonte de variação da análise conjunta foi estimada a contribuição de cada uma delas para a variação total, utilizando-se a estimativa do coeficiente de determinação $\left(\mathrm{R}^{2}\right)$, por meio da expressão: $\mathrm{R}_{\mathrm{i}}^{2}=\frac{\mathrm{SQ}_{\mathrm{i}}}{\mathrm{SQ}_{\mathrm{t}}}$, em que: $\mathrm{SQ}_{\mathrm{i}}$ é a soma de quadrados da fonte de variação $i$; e $S Q_{t}$ é a soma de quadrados total.

Para a análise de estabilidade, foi adotada a metodologia de Annicchiarico (1992), que é baseada no índice de recomendação genotípico, estimado por: $\omega_{\mathrm{i}}=\hat{\mu}_{\mathrm{i}}-\mathrm{z}_{(1-\alpha)} \hat{\sigma}_{\mathrm{z}_{\mathrm{i}}}$, considerando-se todos os ambientes, em que: $\hat{\mu}_{\mathrm{i}}$ é a média percentual do genótipo $i$; $\hat{\sigma}_{z_{\mathrm{i}}}$ é o desvio-padrão dos valores $z_{\mathrm{ij}}$, associado ao i-ésimo genótipo; $\mathrm{z}_{(1-\alpha)}$ é o percentil da função de distribuição normal padrão. $O$ índice foi calculado também para os ambientes favoráveis e desfavoráveis. O coeficiente de confiança adotado foi de $75 \%$, isto é, $\alpha=0,25$.
As análises de estratificação ambiental foram realizadas para cada ano separadamente, utilizandose o método da análise de fatores (MURAKAMI; CRUZ, 2004). O agrupamento dos ambientes foi considerado a partir de cargas fatoriais finais, obtidas após rotações, maiores ou iguais a $0,70 \mathrm{e}$ de mesmo sinal, que indicam ambientes com alta correlação e que podem ser agrupados em um mesmo fator. Segundo Cruz e Carneiro (2006), nessa análise o número de fatores finais considerado na estratificação ambiental pode ser definido pelo número de autovalores que são iguais ou superiores a 1,0. Porém, quando a proporção da variação explicada pelos autovalores maiores que 1,0 for relativamente baixa, consideram-se mais fatores, até que se atinja pelo menos $80 \%$ da variabilidade total. Assim, foram considerados redundantes locais com cargas fatoriais maiores que 0,70 presentes nos fatores que agruparam maior número de ambientes.

\section{Resultados e Discussão}

Os valores do coeficiente de variação para a produtividade de grãos nos ensaios variaram de $7,6 \%$ a 20,4\%, mostrando boa precisão experimental (Tabela 1), que foi confirmada pelas estimativas de acurácia seletiva, consideradas altas ou muito altas (acima de 0,7) (CARGNELUTTI FILHO; STORCK; RIBEIRO, 2009) para nove dos dez experimentos. A produtividade média nos ensaios variou de $1.046 \mathrm{~kg} \mathrm{ha}^{-1}$ a $2.810 \mathrm{~kg} \mathrm{ha}^{-1}$, indicando variabilidade ambiental. Isso pode ser confirmado observando-se os dados geográficos dos locais de avaliação que mostram altitude variando de 305 metros a 716 metros, latitude variando de $8^{\circ} 17^{\prime}$ a $9^{\circ} 23^{\prime}$ e longitude variando de $35^{\circ} 58^{\prime}$ a $40^{\circ} 30^{\prime}$. Considerando os locais com ensaios nos dois anos, a produtividade alcançada no ano de $2007(2.275 \mathrm{~kg}$ $\left.\mathrm{ha}^{-1}\right)$ foi maior do que em $2008\left(1.582 \mathrm{~kg} \mathrm{ha}^{-1}\right)$. 
Tabela 1. Informações geográficas dos locais ${ }^{1}\left(\right.$ altitude $^{2}$, latitude ${ }^{3}$ e longitude oeste ${ }^{4}$ ) e resumos das análises de variância individuais para produtividade de grãos dos 10 ensaios de feijoeiro-comum conduzidos na época de semeadura das "águas", no Estado de Pernambuco em 2007 e 2008.

\begin{tabular}{|c|c|c|c|c|c|c|c|c|c|c|}
\hline Local $^{1}$ & $\mathrm{Alt}^{2}$ & Lat. $^{3}$ & Long. ${ }^{4}$ & $\mathrm{QMg}^{5}$ & $\mathrm{QMe}^{6}$ & $\mathrm{~F}^{7}$ & $\mathrm{P}^{8}$ & Média $^{9}$ & $\mathrm{CV}^{10}$ & $\mathrm{AS}^{11}$ \\
\hline & & & & & 2007 & & & & & \\
\hline SAO & 716 & $8^{\circ} 52^{\prime}$ & $36^{\circ} 22^{\prime}$ & 230.021 & 85.131 & 2,70 & 0,010 & 2.810 & 10,4 & 0,79 \\
\hline CAR & 554 & $8^{\circ} 17^{\prime}$ & $35^{\circ} 58^{\prime}$ & 713.040 & 73.356 & 9,72 & 0,000 & 1.415 & 19,1 & 0,95 \\
\hline $\mathrm{ARC}$ & 663 & $8^{\circ} 25^{\prime}$ & $37^{\circ} 03^{\prime}$ & 231.152 & 33.881 & 6,82 & 0,000 & 2.436 & 7,6 & 0,92 \\
\hline BEL & 305 & $8^{\circ} 45^{\prime}$ & $38^{\circ} 57^{\prime}$ & 312.014 & 145.267 & 2,15 & 0,036 & 2.439 & 15,6 & 0,73 \\
\hline & & & & & 2008 & & & & & \\
\hline SAO & 716 & $8^{\circ} 52^{\prime}$ & $36^{\circ} 22^{\prime}$ & 92.453 & 19.401 & 4,77 & 0,000 & 1.614 & 8,6 & 0,89 \\
\hline PET & 376 & $9^{\circ} 23^{\prime}$ & $40^{\circ} 30^{\prime}$ & 169.142 & 115.180 & 1,47 & 0,180 & 2.545 & 13,3 & 0,56 \\
\hline BEL & 305 & $8^{\circ} 45^{\prime}$ & $38^{\circ} 57^{\prime}$ & 258.754 & 78.373 & 3,30 & 0,003 & 1.712 & 16,3 & 0,83 \\
\hline CAR & 554 & $8^{\circ} 17^{\prime}$ & $35^{\circ} 58^{\prime}$ & 318.976 & 20.221 & 15,77 & 0,000 & 1.046 & 13,6 & 0,97 \\
\hline ARC & 663 & $8^{\circ} 25^{\prime}$ & $37^{\circ} 03^{\prime}$ & 510.421 & 158.991 & 3,21 & 0,003 & 1.954 & 20,4 & 0,83 \\
\hline PET & 376 & $9^{\circ} 23^{\prime}$ & $40^{\circ} 30^{\prime}$ & 130.479 & 59.021 & 2,21 & 0,031 & 2.316 & 10,5 & 0,74 \\
\hline
\end{tabular}

${ }^{5}$ Quadrado médio de genótipos; ${ }^{6}$ Quadrado médio do erro; ${ }^{7}$ Valor do teste F para genótipos; ${ }^{8} \mathrm{P}$-valor; ${ }^{9} \mathrm{Média}$ geral do ensaio (kg. ha $\left.^{-1}\right) ;{ }^{10}$ Coeficiente de variação (\%); ${ }^{11}$ Acurácia seletiva; SAO-São João; CAR-Caruaru; ARC-Arco Verde; BEL-Belém do São Francisco; PET-Petrolina.

Fonte: Elaboração dos autores.

As análises conjuntas para produtividade de grãos e massa de 100 grãos mostraram diferenças entre genótipos, entre ambientes e também a presença da interação $\mathrm{G} \times \mathrm{E}$, o que significa que existe resposta diferencial dos genótipos aos ambientes (Tabela 2).

Tabela 2. Resumo da análise de variância conjunta para a produtividade de grãos $\left(\mathrm{kg} \cdot \mathrm{ha}^{-1}\right)$ dos 10 experimentos de feijoeiro-comum conduzidos no Estado de Pernambuco, na época das "águas”, em 2007 e 2008.

\begin{tabular}{|c|c|c|c|c|c|c|}
\hline \multirow{2}{*}{ FV } & \multicolumn{3}{|c|}{ Produtividade de grãos } & \multicolumn{3}{|c|}{ Massa de 100 grãos } \\
\hline & $\mathrm{GL}$ & $\mathrm{QM}$ & P-valor & $\mathrm{GL}$ & QM & P-valor \\
\hline Blocos/Ambiente & 20 & 370.680 & - & 10 & 2,1 & - \\
\hline Genótipos (G) & 15 & 705.360 & 0,013 & 15 & 456,4 & 0,000 \\
\hline Ambientes (E) & 9 & 15.529 .034 & 0,000 & 4 & 257,3 & 0,000 \\
\hline $\mathrm{G} \times \mathrm{E}$ & $(103)^{1}$ & 329.285 & 0,000 & 60 & 11,4 & 0,000 \\
\hline Resíduo & $(223)^{1}$ & 106.120 & - & 150 & 0,9 & - \\
\hline Total & 479 & & & 239 & & \\
\hline Média & 2.029 & & & 22,9 & & \\
\hline CV (\%) & 16,1 & & & 4,2 & & \\
\hline
\end{tabular}

FV: Fonte de Variação; GL: Graus de liberdade; QM: Quadrado Médio; ' GL da interação e do erro ajustados (COCHRAN, 1954). Fonte: Elaboração dos autores.

A análise de estabilidade para produtividade de grãos pelo método de Annicchiarico (1992) para todos os ambientes identificou cinco genótipos com Wi superior a $100 \%$ (Tabela 3). Isso indica que esses genótipos têm $75 \%$ de probabilidade de produzirem acima da média do ambiente. Entre esses se destacaram BRS Campeiro (112,8\%), BRS Esplendor (107,8\%), BRS Agreste (103,9\%) e BRS Valente (102,0\%), que devem produzir $12,8 \%, 7,8 \%$, $3,9 \%$ e $2,0 \%$, respectivamente, acima da média. 
Considerando os ambientes desfavoráveis, cinco genótipos mostraram boa adaptação/estabilidade. Entre essas merece destaque a BRS Campeiro, com Wid $=114,0$. Outros três genótipos, BRS Esplendor $(113,6 \%)$, BRS Valente $(111,5 \%)$ e BRS Agreste
(106,4\%), apresentaram bom desempenho. Já para os ambientes favoráveis, cinco genótipos apresentaram Wif acima de 100\%: BRS Campeiro (111,8\%), BRS Marfim (106,4\%), BRS Esplendor (103,9\%), BRS Pontal (102,4\%) e BRS Agreste (101,3\%).

Tabela 3. Médias de produtividade de grãos (PROD), massa de 100 grãos (M100), arquitetura de plantas (ARQ), tolerância ao acamamento (ACA), reação à antracnose (ANT) e estimativas de parâmetros de adaptabilidade/ estabilidade para a produtividade de grãos pelo método de Annicchiarico (1992) ( $\mathrm{W}_{\mathrm{i}}$ - Índice de recomendação), com decomposição em ambientes favoráveis $\left(\mathrm{W}_{\mathrm{if}}\right)$ e desfavoráveis $\left(\mathrm{W}_{\mathrm{id}}\right)$, de 16 genótipos de feijoeiro-comum avaliados em Pernambuco.

\begin{tabular}{lcccccccccccc}
\hline \multirow{2}{*}{ Genótipo } & \multirow{2}{*}{ Tipo de grão } & \multirow{2}{*}{ PROD } & \multirow{2}{*}{ M100 } & \multirow{2}{*}{ ARQ } & \multirow{2}{*}{ ACA } & \multirow{2}{*}{ ANT } & \multicolumn{6}{c}{ Annicchiarico } \\
\cline { 8 - 14 } & & & & & & Wi & $\mathrm{C}^{(1)}$ & $\mathrm{W}_{\text {id }}$ & $\mathrm{C}$ & $\mathrm{W}_{\text {if }}$ & $\mathrm{C}$ \\
\hline Campeiro & Preto & $2.365 \mathrm{a}$ & $24,4 \mathrm{~b}$ & 3,7 & 2,3 & 1,6 & 112,8 & 1 & 114,0 & 1 & 111,8 & 1 \\
Esplendor & Preto & $2.235 \mathrm{~b}$ & $17,4 \mathrm{~h}$ & 3,3 & 3,3 & 1,7 & 107,8 & 2 & 113,6 & 2 & 103,9 & 3 \\
Agreste & Mulatinho & $2.184 \mathrm{~b}$ & $22,5 \mathrm{~d}$ & 3,0 & 2,0 & 1,3 & 103,9 & 3 & 106,4 & 4 & 101,3 & 5 \\
Marfim & Mulatinho & $2.178 \mathrm{~b}$ & $22,4 \mathrm{~d}$ & 5,0 & 4,3 & 1,5 & 100,5 & 5 & 94,8 & 7 & 106,4 & 2 \\
Valente & Preto & $2.111 \mathrm{~b}$ & $20,6 \mathrm{e}$ & 3,3 & 3,5 & 1,2 & 102,0 & 4 & 111,5 & 3 & 94,9 & 11 \\
Pontal & Carioca & $2.091 \mathrm{~b}$ & $22,5 \mathrm{~d}$ & 6,7 & 7,1 & 1,1 & 99,0 & 6 & 95,7 & 6 & 102,4 & 4 \\
Princesa & Carioca & $2.008 \mathrm{c}$ & $19,5 \mathrm{f}$ & 5,0 & 5,8 & 2,2 & 91,9 & 9 & 88,1 & 11 & 96,3 & 9 \\
Pioneiro & Carioca & $1.993 \mathrm{c}$ & $18,1 \mathrm{~g}$ & 3,7 & 4,0 & 1,3 & 89,6 & 14 & 83,6 & 14 & 98,2 & 8 \\
Supremo & Preto & $1.991 \mathrm{c}$ & $20,7 \mathrm{e}$ & 3,0 & 2,6 & 1,0 & 96,1 & 7 & 100,6 & 5 & 91,9 & 14 \\
Estilo & Carioca & $1.968 \mathrm{c}$ & $23,1 \mathrm{c}$ & 3,0 & 3,4 & 1,0 & 93,7 & 8 & 89,4 & 10 & 98,5 & 7 \\
Grafite & Preto & $1.955 \mathrm{c}$ & $22,4 \mathrm{~d}$ & 4,7 & 3,9 & 1,5 & 91,1 & 10 & 87,9 & 12 & 95,1 & 10 \\
Radiante & Rajado & $1.916 \mathrm{c}$ & $42,3 \mathrm{a}$ & 4,7 & 4,4 & 1,4 & 88,2 & 15 & 78,8 & 15 & 99,6 & 6 \\
Requinte & Carioca & $1.897 \mathrm{c}$ & $20,7 \mathrm{e}$ & 5,3 & 5,1 & 2,5 & 89,6 & 13 & 87,6 & 13 & 92,6 & 12 \\
Horizonte & Carioca & $1.895 \mathrm{c}$ & $23,6 \mathrm{c}$ & 3,3 & 2,9 & 1,0 & 90,8 & 12 & 92,2 & 9 & 89,1 & 15 \\
Cometa & Carioca & $1.892 \mathrm{c}$ & $22,2 \mathrm{~d}$ & 3,7 & 3,0 & 1,0 & 90,9 & 11 & 93,4 & 8 & 88,4 & 16 \\
Pérola & Carioca & $1.782 \mathrm{c}$ & $22,2 \mathrm{~d}$ & 5,0 & 6,0 & 3,9 & 79,4 & 16 & 68,5 & 16 & 92,1 & 13 \\
\hline
\end{tabular}

Médias seguidas da mesma letra são estatisticamente semelhantes (Scott-Knott, $\alpha=0,10)$; ${ }^{(1)}$ Classificação dos genótipos quanto a estabilidade, sendo 1, o mais estável.

Fonte: Elaboração dos autores.

Uma maneira de confirmar a adaptação ampla dos genótipos é observar, além do Wi (índice de recomendaçãogenotípica do genótipo em geral), se os genótipos apresentam Wif (índice de recomendação genotípica do genótipo nos ambientes favoráveis) e Wid (índice de recomendação genotípica do genótipo nos ambientes desfavoráveis) superiores a $100 \%$. Nesse sentido, merece destaque a BRS Campeiro, de grãos pretos, que foi o genótipo mais produtivo e mais estável (Tabela 3). Entre os cinco genótipos do segundo grupo de maior produtividade, constatou-se que BRS Esplendor (de grão preto) e BRS Agreste (de grão mulatinho) apresentaram estimativas superiores a 100\%, sendo, portanto, indicadas para utilização em qualquer ambiente. Alguns genótipos mostraram adaptação/ estabilidade específica a determinados tipos de ambientes, como BRS Valente (Wid $=111,5 \%$ e Wif $=94,9 \%$ ) para ambientes desfavoráveis e BRS Marfim (Wid=94,8\% e Wif=106,4\%) e BRS Radiante (Wif $=95,7 \%$ e Wid $=102,4 \%$ ), para ambientes favoráveis.

Entre os seis genótipos mais produtivos, três foram de grãos pretos (BRS Campeiro, BRS 
Esplendor e BRS Valente), dois de grãos mulatinhos (BRS Agreste e BRS Marfim) e apenas um de grãos carioca (BRS Pontal) (Tabela 3). Portanto, nota-se que os genótipos de grãos pretos foram mais produtivos do que os de grão carioca. Esse fato merece ser ressaltado, visto que os grãos de maior importância na região nordeste do Brasil são o carioca e o mulatinho, em detrimento do tipo preto, pouco cultivado nessa região. Os genótipos do grupo preto são em média mais eretos do que os do grupo carioca, o que pode favorecer a maior produtividade, visto que na região nordeste, a época de cultivo do feijoeiro-comum coincide com alta pluviosidade, ocasionando grande perda na colheita, em função do contato das vagens com o solo. O bom desempenho dos genótipos do grupo mulatinho já era esperado, visto que são genótipos selecionados para as condições da região nordeste. A adaptação diferenciada de genótipos a determinadas regiões é comum, conforme relatado em vários trabalhos, como os de Pereira et al. (2009a; 2009b), realizados nas regiões central e centro sul do Brasil, nos quais o BRS Estilo foi considerado o genótipo mais estável/ adaptado entre os 16 avaliados. A cultivar BRS Campeiro já foi identificada como altamente estável e adaptada na região centro sul do Brasil (MELO et al., 2007).

Além da produtividade de grãos, outros caracteres são importantes na aceitação de uma cultivar em uma região. O tamanho dos grãos, indicado pela massa de 100 grãos (M100), varia com a cultivar, é muito influenciado pelo ambiente e tem grande importância para o mercado consumidor (CARBONELL et al., 2010). A M100 preferida pelo mercado varia com o tipo de grão, sendo que os grãos do tipo carioca preferidos tem massa em torno de 27g/100 sementes. A M100 dos genótipos ficou abaixo do que é relatado normalmente (Tabela 3) (DEL PELOSO et al., 2009), o que pode ser explicado pelo fato de que nesses ensaios não foi realizado controle químico de doenças. Isso pode ser observado pela M100 da cultivar Pérola (22,2g), que normalmente é de $27,0 \mathrm{~g}$ sendo o padrão para grãos do tipo carioca. Considerando os genótipos de grão tipo carioca, os genótipos BRS Estilo, BRS Horizonte, BRS 9435 Cometa e BRS Pontal apresentaram M100 semelhante ou superior à da cultivar Pérola.

A arquitetura de plantas ereta e a tolerância ao acamamento tem grande importância, pois reduzem as perdas durante a colheita mecânica e evitam que as vagens fiquem em contato com o solo, o que causa deterioração da qualidade comercial dos grãos. Com relação às notas de arquitetura de planta e acamamento, consideraram-se como eretas e tolerantes os genótipos com notas médias abaixo de 4,0. A resistência à antracnose também é de grande importância, visto que essa doença está entre as mais importantes da cultura, podendo causar perdas de até $100 \%$. Foram considerados resistentes genótipos com notas médias abaixo de 3 .

Considerando também os outros caracteres avaliados (Tabela 3), além de alta produtividade, estabilidade e adaptabilidade, merecem destaque os genótipos: BRS Campeiro, de grãos pretos, por ter apresentado maior tamanho de grão, arquitetura ereta, tolerância ao acamamento e moderada resistência a antracnose; e BRS Agreste, de grãos mulatinhos, pois apresenta arquitetura ereta, tolerância ao acamamento e alta resistência à antracnose. Entre os genótipos de grãos carioca, o de melhor desempenho foi o BRS Pontal, que embora apresente arquitetura prostrada e baixa tolerância ao acamamento, esteve entre as mais produtivas e entre as mais adaptadas/estáveis nos ambientes favoráveis, além de apresentar grãos com tamanho padrão comercial e alta resistência à antracnose. Esses genótipos tem grande potencial para utilização como genitores em programas de melhoramento para a região nordeste do Brasil.

A análise com decomposição da interação genótipos $\times$ ambientes em genótipos $\times$ anos $\mathrm{e}$ genótipos $\times$ locais mostrou diferenças significativas para todas as fontes de variação (Tabela 4). Embora tenham sido detectadas diferenças entre 
os genótipos, pode-se observar que entre as fontes de variação principais, genótipos foi a de menor importância (5,9\%), indicando que as maiores diferenças foram entre os anos $(25,3 \%)$ e os locais $(34,8 \%)$, como demonstram os valores de $R^{2}$. Em trabalhos com feijoeiro-comum, Pereira et al. (2010c; 2011) no Paraná/Santa Catarina e Goiás/ Distrito Federal, respectivamente, encontraram as fontes de variação genótipos e anos como mais importantes em relação a locais. Torga et al. (2013) encontraram maior importância para a fonte de variação anos, com genótipos e locais apresentando importância semelhante e menor em relação a anos. Já Ramalho, Abreu e Santos (1998) em Minas Gerais, encontraram resultados semelhantes aos do presente trabalho. É importante lembrar que no presente trabalho e também no de Ramalho, Abreu e Santos (1998) foram utilizados mais locais (quatro e três, respectivamente) do que nos de Pereira et al. (2010c; 2011) e Torga et al. (2013), o que aumenta a chance de aumento de variação entre locais.

Tabela 4. Resumo da análise de variância conjunta, com decomposição da interação genótipos x ambientes, para a produtividade de grãos $\left(\mathrm{kg} \mathrm{ha}^{-1}\right)$ de oito experimentos de feijoeiro-comum, conduzidos no Estado de Pernambuco em 2007 e 2008.

\begin{tabular}{|c|c|c|c|c|c|c|}
\hline Fonte de Variação & GL & SQ & QM & $\mathrm{Fc}$ & P-valor & $\mathrm{R}^{2}$ \\
\hline Bloco/Ambiente & 16 & 4.396 .661 & 274.791 & 3,58 & 0,0000 & 2,42 \\
\hline Genótipos (G ) & 15 & 10.686 .752 & 712.450 & 9,27 & 0,0000 & 5,87 \\
\hline Locais (L) & 3 & 63.326 .736 & 21.108.912 & 274,77 & 0,0000 & 34,80 \\
\hline $\operatorname{Anos}(\mathrm{A})$ & 1 & 46.115 .339 & 46.115 .339 & 600,27 & 0,0000 & 25,34 \\
\hline $\mathrm{G} \times \mathrm{L}$ & 45 & 13.119 .687 & 291.549 & 3,80 & 0,0000 & 7,21 \\
\hline $\mathrm{G} \times \mathrm{A}$ & 15 & 3.646 .108 & 243.074 & 3,16 & 0,0001 & 2,00 \\
\hline $\mathrm{L} \times \mathrm{A}$ & 3 & 9.698 .039 & 3.232 .680 & 42,08 & 0,0000 & 5,33 \\
\hline Gx L x A & 45 & 12.548 .438 & 278.854 & 3,63 & 0,0000 & 6,90 \\
\hline Resíduo & 240 & 18.437 .832 & 76.824 & - & - & 10,13 \\
\hline Total & 383 & 181.975 .606 & - & - & - & - \\
\hline Média & 1.928 & & & & & \\
\hline CV (\%) & 14,7 & & & & & \\
\hline
\end{tabular}

GL: Graus de liberdade; SQ: Soma de quadrados; QM: Quadrado médio; F : Valor do teste F para genótipos; R²: Coeficiente de determinação.

Fonte: Elaboração dos autores.

As interações genótipos $\times$ locais $(\mathrm{G} \times \mathrm{L})$ e genótipos $\times$ anos $(\mathrm{G} \times \mathrm{A})$ foram significativas, representando $7,2 \%$ e $2,0 \%$ da variação total (Tabela 4), indicando que a interação $\mathrm{G} \times \mathrm{L}$ é mais importante que a $\mathrm{G} \times \mathrm{A}$ e, que, consequentemente, a avaliação em mais locais é mais importante do que em mais anos. Pereira et al. (2010c) obtiveram resultados semelhantes, já que observaram que a interação mais importante foi $\mathrm{G} \times \mathrm{L}, 0,7$ vezes maior que a $\mathrm{G} \times$ A. Já Ramalho, Abreu e Santos (1998) encontraram $\mathrm{R}^{2}$ muito semelhantes para essas interações, sendo a $\mathrm{G} \times \mathrm{L}$ não significativa.
Pereira et al. (2011) e Torga et al. (2013) obtiveram a interação $G \times A$ 0,4 vezes mais importante do que a $\mathrm{G} \times \mathrm{L}$. Os resultados obtidos no presente trabalho indicam que existe interação entre os genótipos, locais e anos, no estado de Pernambuco, o que faz com que os genótipos tenham que ser avaliados no maior número possível de locais e anos, nessa ordem de importância, para que se faça indicação mais segura dos genótipos. Embora a quantidade de locais (quatro) e de anos (dois) não seja muito grande, ela é compatível com os estudos semelhantes realizados na cultura do feijoeiro comum em outros estados, 
e além disso, a quantidade de locais é superior à exigida pelas normas para registro de cultivares de feijoeiro-comum, que exigem experimentos em pelo menos dois anos e três locais para cada época de semeadura em um determinado estado (BRASIL, 2012). Assim, mesmo com a limitação na quantidade de locais e anos, esses resultados são importantes, principalmente quando se considera um estado com menor extensão territorial, como é o caso de Pernambuco e sobre o qual ainda não existem informações disponíveis sobre a importância dos componentes da interação.

A estratificação ambiental, no ano de 2007 foi realizada com três fatores finais, que explicaram $90,5 \%$ da variação (Tabela 5). No primeiro fator agruparam-se os locais São João $(0,91)$ e Arco verde $(0,82)$, que foram classificados como redundantes, uma vez que os demais fatores ficaram com apenas um local. Já no ano de 2008, foram utilizados quatro fatores, que explicaram $89,0 \%$ da variação total. No primeiro fator agruparam-se os dois ensaios de Petrolina (0,90 e 0,77), conduzidos em diferentes áreas, mostrando a confiabilidade da análise, conforme tem sido relatado em outros trabalhos (OLIVEIRA et al., 2005). Entretanto, os demais locais não foram agrupados. Dessa forma, a redundância entre São João e Arco Verde obtida no ano de 2007 não foi confirmada em 2008. Por isso, conclui-se que os locais utilizados (Arco Verde, Belém de São Francisco, Petrolina, São João e Caruaru) devem ser mantidos na rede de avaliação de ensaios em Pernambuco, visto que não foram encontrados padrões consistentes de semelhança entre os locais ao longo dos anos. É importante mencionar que a incorporação de novos locais é desejável, já que foi detectada grande importância da interação G×L (Tabela 4).

Tabela 5. Estratificação ambiental baseada na produtividade de grãos, por meio da análise de fatores, por ano, com 16 genótipos de feijoeiro-comum avaliados em 10 ensaios na safra das águas em Pernambuco nos anos de 2007 e 2008.

\begin{tabular}{|c|c|c|c|c|c|c|c|c|}
\hline \multicolumn{3}{|c|}{ Autovalores } & \multicolumn{6}{|c|}{ Cargas Fatoriais Após Rotação } \\
\hline Fator & $\lambda^{1}$ & $\% \%^{2}$ & Ambientes & Fator 1 & Fator 2 & Fator 3 & Fator 4 & $\Phi^{3}$ \\
\hline \multicolumn{9}{|c|}{2007} \\
\hline 1 & 1,58 & 39,58 & São João & 0,91 & 0,22 & $-0,14$ & - & 0,89 \\
\hline 2 & 1,33 & 72,90 & Caruaru & 0,01 & 0,93 & 0,24 & - & 0,93 \\
\hline 3 & 0,70 & 90,51 & Arco Verde & 0,82 & $-0,29$ & 0,33 & - & 0,86 \\
\hline- & 0,37 & 100,00 & B. do São Francisco & 0,04 & 0,25 & 0,94 & - & 0,94 \\
\hline \multicolumn{9}{|c|}{2008} \\
\hline 1 & 1,83 & 30,48 & São João & 0,09 & 0,07 & 0,17 & $-0,98$ & 0,99 \\
\hline 2 & 1,56 & 56,53 & Petrolina & 0,90 & $-0,13$ & $-0,05$ & $-0,13$ & 0,85 \\
\hline 3 & 1,23 & 76,96 & B. do São Francisco & 0,07 & $-0,10$ & 0,93 & $-0,18$ & 0,92 \\
\hline 4 & 0,72 & 89,01 & Caruaru & $-0,53$ & 0,65 & 0,36 & $-0,09$ & 0,83 \\
\hline- & 0,38 & 95,27 & Arco Verde & 0,13 & 0,90 & $-0,21$ & $-0,05$ & 0,87 \\
\hline- & 0,28 & 100,00 & Petrolina 1 & $\mathbf{0 , 7 7}$ & 0,40 & 0,34 & $-0,02$ & 0,88 \\
\hline
\end{tabular}

${ }^{1}$ Autovalores; ${ }^{2}$ Porcentagem acumulada da variação explicada pelos autovalores; ${ }^{3}$ Comunalidades.

Fonte: Elaboração dos autores.

\section{Conclusões}

A interação genótipos $\mathrm{x}$ ambientes é importante para a produtividade e massa de cem grãos em feijoeiro-comum, no Estado de Pernambuco.
Os genótipos BRS Campeiro e BRS Esplendor, de grãos pretos, BRS Agreste, de grãos mulatinhos e BRS Pontal, de grãos carioca, apresentam alta adaptabilidade e estabilidade, sendo os mais 
indicados para semeadura em Pernambuco e, consequentemente, são indicados para utilização como genitores em programas de melhoramento visando desenvolvimento de novos genótipos para essa região.

Os locais São João, Caruaru, Arco Verde e Belém do São Francisco fornecem informações complementares para a avaliação de genótipos de feijoeiro-comum em Pernambuco.

Existe interação entre os genótipos de feijoeiro-comum, locais e anos, em Pernambuco, e, consequentemente, os genótipos devem ser avaliados no maior número possível de locais e anos, nessa ordem de importância.

\section{Agradecimentos}

À Embrapa Arroz e Feijão e ao Instituto Agronômico de Pernambuco, pelo financiamento do trabalho. Ao CNPq pela concessão de bolsa de produtividade em desenvolvimento tecnológico e extensão inovadora ao primeiro e terceiro autores.

\section{Referências}

ANNICCHIARICO, P. Cultivar adaptation and recommendation from alfafa trials in Northern Italy. Journal of Genetics and Plant Breeding, Rome, v. 46, n. 1, p. 269-278, 1992.

BERTOLDO, J. G.; COIMBRA, J. L. M.; NODARI, B. O.; GUIDOLIN, A. F.; HEMP, S.; BARILI, L. D.; VALE, N. M.; ROZZETO, D. S. Stratification of the state of Santa Catarina in macro-environments for bean cultivation. Crop Breeding and Applied Biotechnology, Londrina, v. 9, n. 4, p. 335-343, 2009.

BRASIL. Instrução Normativa $\mathrm{n}^{\circ} 25$, de 23 de maio de 2006. Anexo I. Requisitos mínimos para determinação do valor de cultivo e uso de feijão (Phaseolus vulgaris) para a inscrição no registro nacional de cultivares - RNC. Diário Oficial [da] República Federativa do Brasil, Brasília, DF, 19 jun. 2006. Disponível em: <http:// extranet.agricultura.gov.br/sislegisconsulta/servlet/ VisualizarAnexo?id=11376>. Acesso em: 10 mar. 2012.

CARBONELL, S. A. M.; POMPEU, A. S. Estratificação de ambientes em experimentos de feijoeiro no Estado de
São Paulo. Bragantia, Campinas, v. 56, n. 1, p. 207-218, 1997.

CARBONELL, S. A. M.; CHIORATO, A. F.; GONÇALVES, J. G. R.; PERINA, E. F.; CARVALHO, C. R. L. Tamanho de grão comercial em cultivares de feijoeiro. Ciência Rural, Santa Maria, v. 40, n. 10, p. 2067-2073, 2010.

CARGNELUTTI FILHO, A.; STORCK, L.; RIBEIRO, N. D. Medidas da precisão experimental em ensaios com genótipos de feijão e de soja. Pesquisa Agropecuária Brasileira, Brasília, v. 44, n. 10, p. 1225-1231, 2009.

CARVALHO, H. W. L.; FARIA, L. C.; DEL PELOSO, M. J.; RIBEIRO, F. E.; MELO, L. C.; OLIVEIRA, V. D.; RIBEIRO, S. S. Adaptabilidade e estabilidade de cultivares de feijoeiro comum na Zona Agreste do Nordeste Brasileiro. Agrotrópica, Ilhéus, v. 20, n. 1, p. 21-24, 2008.

COCHRAN, W. G. The combination of estimates from different experiments. Biometrics, Washington, v. 10, n. 1, p. 101-129, 1954.

COSTA, J. G. C.; MELO, L. C.; PEREIRA, H. S.; DEL PELOSO, M. J.; FARIA, L. C.; DÍAZ, J. L. C.; WENDLAND, A.; RAVA, C. A. BRS esplendor: common bean cultivar with black grain, upright growth and disease resistance. Crop Breeding and Applied Biotechnology, Londrina, v. 11, n. 3, p. 276-279, 2011.

CRUZ, C. D. Programa genes: aplicativo computacional em genética e estatística: versão Windows. Viçosa: Editora UFV, 2001. 648 p.

CRUZ, C. D.; CARNEIRO, P. C. Modelos biométricos aplicados ao melhoramento genético. Viçosa: UFV, 2006. v. 2, 585 p.

CRUZ, C. D.; REGAZZI, A. J. Modelos biométricos aplicados ao melhoramento genético. Viçosa: UFV, 2001. 390 p.

DEL PElOSO, M. J.; MELO, L. C.; PEREIRA, H. S.; FARIA, L. C.; DIAZ, J. L. C.; WENDLAND, A. Cultivares de feijoeiro comum desenvolvidas pela Embrapa. In: FANCELI, A. L. (Ed.). Feijão - tópicos especias de manejo. 2. ed. Piracicaba: ESALQ/USP/ LPV, 2009. p. 23-40.

DOMINGUES, L. S.; RIBEIRO, N. D.; MINETTO, C.; SOUZA, J. F.; ANTUNES, I. F. Metodologias de análise de adaptabilidade e de estabilidade para a identificação de linhagens de feijão promissoras para o cultivo no Rio Grande do Sul. Semina: Ciências Agrárias, Londrina, v. 34, n. 3, p. 1065-1076, 2013.

FEIJÃO: dados conjunturais do feijão (área, produção e rendimento) - Brasil - 1985 a 2009. 2011. Disponível 
em: <http://www.cnpaf.embrapa.br/apps/socioeconomia/ index.htm>. Acesso em: 20 maio 2011.

FERREIRA, D. F. Sistema para análise de variância para dados balanceados (SISVAR). Lavras: Editora UFLA, 1999. $92 \mathrm{p}$.

GONÇALVES, J. G. R.; CHIORATO, A. F.; PERINA, E. F.; CARBONELL, S. A. M. Estabilidade fenotípica em feijoeiro estimada por análise ammi com genótipo suplementar. Bragantia, Campinas, v. 68, n. 4, p. 863871, 2009.

MELO, L. C. (Ed.). Procedimentos para condução de ensaios de valor de cultivo e uso em feijoeiro-comum. Santo Antônio de Goiás: Embrapa Arroz e Feijão, 2009. 104 p. (Documentos, 239).

MELO, L. C.; DEL PELOSO, M. J.; PEREIRA, H. S.; FARIA, L. C.; COSTA, J. G. C.; DÍAZ, J. L. C.; RAVA, C. A.; WENDLAND, A.; ABREU, A. F. B. BRS estilo: common bean cultivar with carioca grain, upright growth and high yield potential. Crop Breeding and Applied Biotechnology, Londrina, v. 10, n. 4, p. 377-379, 2010.

MELO, L. C.; SANTOS, P. G.; FARIA, L. C.; DIAZ, J. L. C.; DEL PELOSO, M. J.; RAVA, C. A.; COSTA, J. G. C. Interação com ambientes e estabilidade de genótipos de feijoeiro-comum na Região Centro-Sul do Brasil. Pesquisa Agropecuária Brasileira, Brasília, v. 42, n. 5, p. 715-723, 2007.

MURAKAMI, D. M.; CRUZ, C. D. Proposal of methodologies for environment stratification and analysis of genotype adaptability. Crop Breeding and Applied Biotechnology, Londrina, v. 4, n. 1, p. 7-11, 2004.

OLIVEIRA, G. V.; CARNEIRO, P. C. S.; DIAS, L. A. S.; CARNEIRO, J. E. S.; CRUZ, C. D. Factor analysis in the environment stratification for the evaluation of common bean cultivars. Crop Breeding and Applied Biotechnology, Londrina, v. 5, n. 4, p. 166-173, 2005.

PEREIRA, H. S.; MELO, L. C.; DEL PELOSO, M. J.; FARIA, L. C. de; WENDLAND, A. Complex interaction between genotypes and growing seasons of carioca common bean in Goiás/Distrito Federal. Crop Breeding and Applied Biotechnology, Londrina, v. 10, n. 3, p. 207215, 2011.

PEREIRA, H. S.; MELO, L. C.; FARIA, L. C. de; DEL PELOSO, M. J.; DÍAZ, J. L. C.; WENDLAND, A. Indicação de cultivares de feijoeiro-comum baseada na avaliação conjunta de diferentes épocas de semeadura.
Pesquisa Agropecuária Brasileira, Brasília, v. 45, n. 6, p. 571-578, 2010c.

PEREIRA, H. S.; MELO, L. C.; FARIA, L. C. de; DÍAZ, J. L. C.; DEL PELOSO, M. J.; COSTA, J. G. C.; FERREIRA, A. W. Stability and adaptability of carioca common bean genotypes in states of the central South Region of Brazil. Crop Breeding and Applied Biotechnology, Londrina, v. 9, n. 2, p. 181-188, 2009b.

PEREIRA, H. S.; MELO, L. C.; FARIA, L. C.; DEL PELOSO, M. J.; COSTA, J. G. C.; RAVA, C. A.; WENDLAND, A. Adaptabilidade e estabilidade de genótipos de feijoeiro-comum com grãos tipo carioca na Região Central do Brasil. Pesquisa Agropecuária Brasileira, Brasília, v. 44, n. 1, p. 29-37, 2009a.

PEREIRA, H. S.; MELO, L. C.; FARIA, L. C.; DEL PELOSO, M. J.; WENDLAND, A. Estratificação ambiental na avaliação de genótipos de feijoeiro-comum tipo Carioca em Goiás e no Distrito Federal. Pesquisa Agropecuária Brasileira, Brasília, v. 45, n. 6, p. 554-562, 2010a.

PEREIRA, H. S.; MELO, L. C.; FARIA, L. C.; DEL PELOSO, M. J.; WENDLAND, A. Environmental Stratification in Paraná and Santa Catarina States to evaluate common bean genotypes. Crop Breeding and Applied Biotechnology, Londrina, v. 10, n. 2, p. 132-139, $2010 \mathrm{~b}$.

PIMENTEL-GOMES, F. P. Curso de estatística experimental. São Paulo: Editora Nobel, 2000. 466 p.

RAMALHO, M. A. P.; ABREU, A. F. B.; SANTOS, P. S. J. Interações genótipos $\mathrm{x}$ épocas de semeadura, anos e locais na avaliação de cultivares de feijão nas Regiões sul e Alto Paranaíba em Minas Gerais. Ciência e Agrotecnologia, Lavras, v. 22, n. 2, p. 176-181, 1998.

RESENDE, M. D. V.; DUARTE, J. B. Precisão e controle de qualidade em experimentos de avaliação de cultivares. Pesquisa Agropecuária Tropical, Goiás, v. 37, n. 3, p. 182-194, 2007.

TORGA, P. P.; MELO, P. G. S.; PEREIRA, H. S.; FARIA, L. C.; DEL PELOSO, M. J.; MELO, L. C. Interaction of common bean cultivars of the black group with years, locations and sowing seasons. Euphytica, Wageningen, v. 189 , n. 2, p. 239-248, 2013.

ZIMMERMANN, F. J. P. Estatística aplicada à pesquisa agrícola. Santo Antônio de Goiás: Embrapa Arroz e Feijão, 2004. 402 p. 
